\title{
Cerebral Bioavailability of Silexan- A Quantitative EEG Study in Healthy Volunteers
}

\author{
Wilfried Dimpfel ${ }^{1}$, Winfried Wedekind ${ }^{2}$, Angelika Dienel ${ }^{3}$ \\ ${ }^{1}$ Justus-Liebig-University c/o NeuroCode AG, Wetzlar, Germany \\ ${ }^{2}$ NeuroCode AG, Wetzlar, Germany \\ ${ }^{3}$ Dr. Willmar Schwabe GmbH \& Co. KG, Karlsruhe, Germany \\ Email: angelika.dienel@schwabe.de
}

Received 4 May 2015; accepted 7 June 2015; published 10 June 2015

Copyright (C) 2015 by authors and Scientific Research Publishing Inc.

This work is licensed under the Creative Commons Attribution International License (CC BY). http://creativecommons.org/licenses/by/4.0/

cC) (i) Open Access

\begin{abstract}
Background: A quantitative EEG (qEEG) study was performed to investigate the cerebral bioavailability of Silexan. Method: Twenty-four male and female healthy volunteers between 20 and 62 years of age were eligible for participation and received 160 or $80 \mathrm{mg} /$ day Silexan or placebo in randomised order according to a 3-way crossover design. Treatment phases of 14 days were separated by 14-day washout periods. qEEG recordings in conditions "eyes open", "eyes closed", as well as during performance of 3 different cognitive tasks, were performed at $0,1,2,3$, and $4 \mathrm{~h}$ after drug administration on the first (single-dose assessment) and last day of each treatment period (repetitive dose assessment). Result: Compared with placebo, qEEG analysis revealed a significant increase of spectral power within two hours in the alpha1 range $(7.0$ - $9.5 \mathrm{~Hz})$, particularly in the fronto-temporal region, where it was more pronounced after administration of Silexan 160 $\mathrm{mg} /$ day than after the $80 \mathrm{mg} /$ day dose. Changes in other frequency bands were mainly attributable to circadian rhythm. No EEG changes typically seen during the investigation of sedative drugs (general theta increase) were observed. Cognitive task performance under both doses of Silexan was not inferior compared with that in the placebo period. Conclusions: The study provides evidence that ingredients of the anxiolytic lavender oil preparation Silexan penetrate the blood-brain barrier and induce functional changes in the CNS. The types of changes observed in the qEEG are consistent with the anxiolytic clinical effect of the drug represented by increases of alpha1 spectral power. No sedative effects were observed. Silexan was well tolerated during repetitive administration of doses up to twice the marketed dose.
\end{abstract}

\section{Keywords}

Silexan, Clinical Trial, Cerebral Bioavailability, qEEG, CATEEM 


\section{Introduction}

Herbal preparations are multi-ingredient compounds whose bioavailability is difficult to assess. Bioavailability can depend on chemical complexity of the herb due to synergistic and antagonistic actions of their constituents in promoting absorption, hydrophobic or lipophilic properties influencing the ability to cross luminal wall, gut microflora and hepatic activity of the individual, and chemical modifications of the herbal constituents [1]. This is one reason why establishing the pharmacological basis for efficacy of herbal medicinal products remains a constant challenge [2].

Psychotropic drugs act primarily on the central nervous system (CNS), and thus their cerebral bioavailability is of interest. To be effective in the CNS constituents of a herbal drug have to cross the blood brain barrier. In man, the cerebral bioavailability of psychotropic herbal drugs, like that of any other psychotropic drug, can be assessed using non-invasive methods of quantitative pharmaco-electroencephalography (qEEG; [3]). For decades the technique has been used as a standard procedure for the prediction of whether, where, how, when, and in which dosage the investigated compound acts on the brain [4]. Since their introduction in the 1950s [5] [6], qEEG methods have undergone a still ongoing evolution, supported by the increasing availability of powerful computational resources. In order to obtain an objective quantitative analysis time-dependent voltage level recordings from a pair of electrodes are converted into a spectrogram using Fast Fourier Transformation (FFT) in which pre-defined frequency bands are characterised by their respective electric power.

A major step towards a better understanding of the action of pharmacological substances on the brain was the development of methods of EEG assessments such as Computer-Aided Topographical Electro-Encephalometry $\left(\right.$ CATEEM $^{\circledR}$; [7] [8]) which started during the 1990s. In CATEEM ${ }^{\circledR}$ the spectral power of the frequency bands obtained for different electrode locations is transformed into a set of spectral colours that are mixed according to an additive model to generate a brain map that visualises the distribution of the spectral frequencies over the areas of the cerebral cortex. The investigation of spectral frequency changes in different brain regions can be used for assessing the effects of investigational drugs on the electric activity of the brain as well as for comparing the observed frequency patterns with those of other substances, which have a well-characterised clinical effect [9]. In phytopharmaceutical research CATEEM ${ }^{\circledR}$ technology has been used in a rat model for the classification of herbal extracts by means of comparison to spectral EEG signatures induced by synthetic drugs [10] as well as for the analysis of neurophysiological changes following herbal drug administration in humans (e.g., [11]).

Silexan ${ }^{1}$, the essential oil produced from Lavandula angustifolia, is the active substance of a medicinal product for oral use, which is authorised in Germany for the treatment of restlessness accompanying anxious moods, with a recommended dose of $80 \mathrm{mg}$ once daily. Randomised, double-blind clinical trials have shown that Silexan is a potent anxiolytic drug. In sub-syndromal anxiety disorder Silexan was superior to placebo in reducing the total score of the Hamilton Anxiety Scale (HAMA; [12]) during 10 weeks of treatment [13]. Patients suffering from restlessness, agitation, and disturbed sleep also showed a more pronounced HAMA total score reduction when treated with Silexan than those who received placebo [14]. In patients with syndromal generalised anxiety disorder (GAD) Silexan was superior to placebo and comparably efficacious as paroxetine [15] and as lorazepam [16].

This study was performed to substantiate the psychopharmacological effect of Silexan and to supplement information derived from therapeutic clinical trials, by investigating the bioavailability of the herbal compound in the human CNS using methods of qEEG.

\section{Methods}

\subsection{Design Overview, Ethical Conduct}

The study was a double-blind, placebo-controlled, single-centre, 3-period crossover trial during which healthy volunteers received single and repetitive doses of $160 \mathrm{mg} /$ day and $80 \mathrm{mg} /$ day Silexan and placebo in 1 out of 3 randomised sequences.

The study protocol was reviewed and approved by competent authority and by an independent ethics committee (Ethik-Kommission bei der Landesärztekammer Hessen, FF84/2010). All subjects provided written informed consent. The principles of Good Clinical Practice and the Declaration of Helsinki were adhered to.

\footnotetext{
${ }^{1}$ Silexan $^{\circledR}$ (WS $\left.{ }^{\circledast} 1265\right)$ is the active substance of Lasea ${ }^{\circledR}$ (Dr. Willmar Schwabe GmbH \& Co. KG, Karlsruhe, Germany).
} 


\subsection{Participants}

Study participants were recruited through advertisement. Male and female healthy volunteers between 18 and 65 years of age were eligible for participation. Female participants of childbearing potential were required to have a negative pregnancy test and to use adequate double contraception. Subjects who had participated in any other clinical trial within 3 months before enrolment, who suffered from any acute medical condition, who had a history of diseases of relevant vital organs, of the CNS, or of gastrointestinal disorders that could influence the absorption of orally administered drugs, were excluded. Moreover, subjects with known hypersensitivity to Lavender preparations, with relevantly abnormal safety laboratory values or vital signs, or with massive deviations from normal quantitative EEG parameters were also ineligible.

Smoking up to a maximum of 25 cigarettes per day as well as regular alcohol consumption not exceeding $20 \mathrm{~g}$ per day, were permitted. Any medical or recreational drugs, including over-the-counter preparations and dietary supplements, which could have an effect on the CNS or otherwise interfere with the EEG assessments, were prohibited during and within 2 weeks before trial participation.

\subsection{Interventions, Blinding, Randomisation}

Silexan (WS $\left.{ }^{\circledR} 1265\right)$ is a patented active substance with an essential oil produced from Lavandula angustifolia flowers by steam distillation that complies with the monograph Lavender oil of the European Pharmacopoeia (Ph. Eur.). It exceeds the quality definition of the Ph. Eur. with respect to items important for efficacy and tolerability. The study treatments were available in identical, immediate release soft gelatine capsules. During each treatment phase one capsule of the appropriate study medication was administered at about 8:00 $\mathrm{h}$ in the morning with non-sparkling water at room temperature for 14 consecutive days. The study participants received 160 mg or $80 \mathrm{mg}$ Silexan or placebo.

\subsection{Study Schedule and Assessments}

Following a screening examination which included assessments of medical history, safety laboratory measures, ECG, vital signs as well as a physical examination, eligible subjects were randomised and received the investigational treatments in the allocated sequence. The 3 treatment periods of 14 days' duration were separated by 14-day washout phases. EEG examinations were performed on the first and last day of each treatment period on which the subjects were confined to the investigative unit and received standardised meals. The subjects were questioned for any adverse events during all post-screening visits. A safety follow-up examination was performed within 1 week after study drug discontinuation.

On the examination days the subjects were requested to appear at the experimental unit in time and without prior study medication intake so that the assessments could start at $8 \mathrm{~h}$ in the morning. Following a brief introduction and check-up qEEG recordings of 25 minutes' duration were performed at pre-dose as well as at $1 \mathrm{~h}, 2 \mathrm{~h}$, $3 \mathrm{~h}$, and $4 \mathrm{~h}$ post dose (Figure 1). During the recordings the subjects sat alone in a separate, quiet room in a comfortable easy chair with light dimmed. A baseline recording of 6 min under the condition of "eyes open"

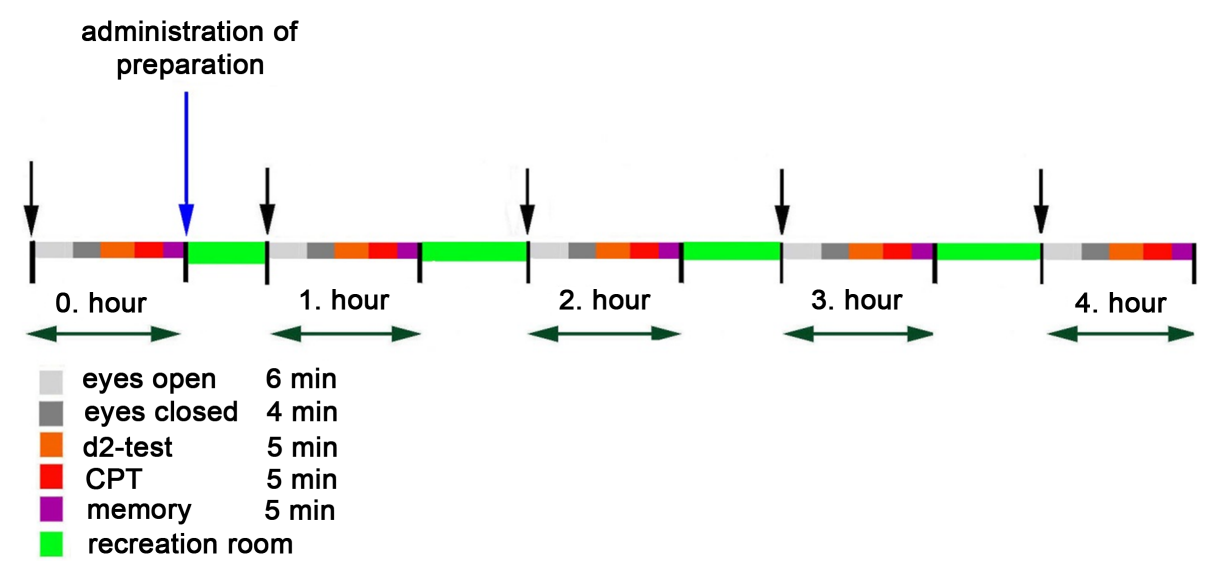

Figure 1. Schedule of EEG recordings during each assessment day. 
was followed by a 4-min recording under the condition of "eyes closed”, which was in turn followed by 5-min recordings during performance of 3 cognitive tests. The d2 Test of Attention [17] has been validated for the neuropsychological estimation of individual attention and short-term concentration performance. The Concentration Performance Test (Konzentrations-Leistungs-Test, KLT; [18] is a validated measure of vigilance while performing mathematical calculation tasks. Moreover, a Memory Test (MT) was performed to assess short-term retention in a recall task following the presentation of nonsense combinations of letters and numbers.

Bipolar EEG recordings were performed using 17 surface electrodes according to the international 10/20 system, with $\mathrm{Cz}$ as physical reference electrode used for calculation of the common average reference. An electrode cap was used for electrode placement. The raw signals were amplified, digitized (2048 Hz/12 bit) and transmitted to the computer via fibre optical devices where they were processed using CATEEM $^{\circledR}$ software (MEWICON CATEEM-Tec GmbH, A-4164 Schwarzenberg, Austria). Artefacts from EEG alterations caused by eye blinks, swallowing, respiration, etc., were rejected using an automated algorithm. An electrooculogram (EOG) was recorded in one channel to facilitate detection of signals superposing the EEG. The artefact rejection set-up was observed for about 5 minutes prior to the start of the recording to ensure that all artefacts were correctly recognized and eliminated from further evaluation. For backup purposes the original raw data (including artefacts) were saved on disk in order to allow a re-evaluation of the artefact rejection if required. The amount of rejected data was determined automatically and given in percent of total recording time. Recording and computer-based automatic artefact rejection were supervised continuously by a trained technician. For each subject settings were kept constant throughout the trial.

In addition to the 17 physical electrodes, signals from 82 additional virtual electrode positions were obtained using Lagrange interpolation, to provide the information required for the generation of high-resolution topographical brain maps. Based on 4-second sweeps of data epochs (Hanning window), the signals from all 99 electrode positions (17 physical and 82 virtual) were FFT transformed into absolute spectral power values in the frequency range between 1.25 and $35 \mathrm{~Hz}$, which was subdivided into the 6 frequency bands of delta $(1.25-4.50$ $\mathrm{Hz})$, theta $(4.75$ - $6.75 \mathrm{~Hz})$, alpha1 $(7.00-9.50 \mathrm{~Hz})$, alpha2 $(9.75$ - $12.50 \mathrm{~Hz})$, beta1 $(12.75$ - $18.50 \mathrm{~Hz})$, and beta2 $(18.75-35.00 \mathrm{~Hz})$. Colour coding of the brain maps was achieved by dividing the power spectrum into 140 equidistant frequency ranges with a resolution of $0.25 \mathrm{~Hz}$ to which spectral colours from red to dark blue were assigned, followed additive colour mixing to obtain the colours at any given point in the topographical map. The maps show the relative, time averaged changes of electrical brain activity of each recording condition in comparison to the reference period during relaxation with open eyes.

\subsection{Random Sequence Generation, Allocation Concealment, Implementation}

For the allocation of the patients to the 3 treatment sequences random numbers were generated by a qualified person in the sponsor's bio-statistical department otherwise not involved in the trial, using a validated computer program (RCODE, Dr. Willmar Schwabe GmbH \& Co. KG, Karlsruhe, Germany). Randomisation was performed in fixed blocks at a ratio of 1:1:1 with stratification by sex. The study drugs were dispensed to the centre in numbered containers. Upon inclusion into randomised treatment each subject received the medication kit with the lowest available medication number. The block size was withheld from the site personnel until completion of the trial.

\subsection{Statistical Methods, Sample Size}

Baseline demographic and anthropometric data were compared descriptively between the 3 treatment sequences and were tested for differences using Kruskal-Wallis tests or $\chi^{2}$ tests as applicable.

For the assessment of spectral power changes in the EEG after drug intake the power values obtained during the "eyes open" and the "eyes closed" conditions at pre-dose were taken as intra-individual reference values and were assumed to represent $100 \%$. All post-dose values were expressed in percent relative to these reference values. Treatment group comparisons for spectral power values as well as for relative change from baseline between Silexan 80 and $160 \mathrm{mg} /$ day on one hand and placebo on the other were performed using non-parametric Sign tests. All p-values are 2-sided and are intended to be descriptive.

No missing data imputation was performed. Subjects were analysed for safety if they had taken at least 1 dose of 1 investigational treatment. They were included into the EEG analysis if they had provided evaluable qEEG data for all 3 treatment periods. 
In this exploratory trial a sample size of 24 subjects (8 in each sequence) was chosen based on practical experience from previous trials with a similar design rather than on power considerations.

\section{Results}

\subsection{Recruitment, Participant Flow}

The clinical part of the trial was performed between February and July 2011 in a clinical phase I unit in Germany. A total of 32 subjects were screened for participation and 24 were randomised, 8 subjects to each of the 3 treatment sequences. Reasons for non-randomisation were violations of eligibility criteria (5 subjects) and conflicts between the study schedule and the subjects' private calendar (3 subjects). All subjects were evaluated for safety. One subject randomised to sequence Silexan 80 mg-Silexan 160 mg-placebo was withdrawn prematurely on the $8^{\text {th }}$ day of the $1^{\text {st }}$ treatment period due to a non-serious but severe, potentially treatment related adverse event (eructation, nausea, and stomach cramps). All other study participants terminated the trial as scheduled and thus 23 subjects were evaluated in the EEG analysis.

\subsection{Baseline Data}

Table 1 shows that the treatment groups were essentially comparable with respect to demographic and anthropometric measures. The randomised study participants' medical history and baseline physical examination did not reveal any findings from which interference with the procedures or the outcomes of the trial could be expected. Baseline concomitant medication was limited to hormonal contraceptives (7 subjects), iodine preparations for struma or after thyroidectomy (4 subjects), acetylsalicylic acid for thromboembolic prophylaxis (1 subject), and alendronic acid for osteoporosis.

\subsection{Treatment Compliance}

Compliance was assessed per treatment period, by comparing the number of unused capsules returned by the subjects to the expected number assuming a fully protocol compliant intake. For all subjects and periods compliance ranged between $93.3 \%$ and $100.0 \%$. On the EEG assessment days none of the subjects took the study medication before the $1^{\text {st }}$ or after the $2^{\text {nd }}$ qEEG recording, so that no relevant protocol deviations related to treatment compliance were observed.

\subsection{Quantitative EEG Analysis}

Table 2 presents the absolute power values for the 17 physical electrodes obtained during pre-dose (baseline) recording on day 1 of each treatment period (i.e., prior to the single dose assessments) in the "eyes closed" condition. For each electrode position and frequency range the data show no baseline differences between placebo on the one hand and one of the doses of Silexan on the other. The same applied to the baseline values for the "eyes open" condition before the first dose of each period as well as to the baseline recordings after repetitive dosing obtained at pre-dose of treatment day 14 of each period in the "eyes open" and "eyes closed" condition (data not shown).

The changes of spectral power in the "eyes closed" condition at $1 \mathrm{~h}, 2 \mathrm{~h}, 3 \mathrm{~h}$ and $4 \mathrm{~h}$ after single dose (acute) administration of the investigational treatments are shown in Figure 2. Changes from baseline in the placebo

Table 1. Demographic and other baseline data (EEG analysis set; absolute frequency (\%) or mean \pm SD).

\begin{tabular}{|c|c|c|c|c|c|}
\hline & & $\begin{array}{l}\text { Silexan } 160 \text { mg-Silexan } \\
80 \text { mg-placebo }(\mathrm{n}=8)\end{array}$ & $\begin{array}{l}\text { Silexan } 80 \text { mg-Silexan } 160 \\
\text { mg-placebo }(\mathrm{n}=7)\end{array}$ & $\begin{array}{c}\text { Placebo-Silexan } \\
80 \text { mg-Silexan } 160 \mathrm{mg}(\mathrm{n}=8)\end{array}$ & $\mathrm{p}$ \\
\hline Sex & $\begin{array}{l}\text { Female } \\
\text { Male }\end{array}$ & $\begin{array}{l}4(50.0 \%) \\
4(50.0 \%)\end{array}$ & $\begin{array}{l}3(42.9 \%) \\
4(57.1 \%)\end{array}$ & $\begin{array}{l}4(50.0 \%) \\
4(50.0 \%)\end{array}$ & $0.95^{\#}$ \\
\hline & Age (years) & $44.3 \pm 10.1$ & $42.3 \pm 10.3$ & $48.9 \pm 13.6$ & $0.29^{\S}$ \\
\hline & Weight (kg) & $74.1 \pm 10.3$ & $78.4 \pm 15.2$ & $77.3 \pm 11.2$ & $0.82^{\S}$ \\
\hline & Height (cm) & $170.9 \pm 10.2$ & $179.6 \pm 11.1$ & $170.5 \pm 8.6$ & $0.29^{\S}$ \\
\hline
\end{tabular}

\footnotetext{
"Pearson $\chi^{2}$-test; ${ }^{\S}$ Kruskal-Wallis test.
} 
Placebo EC 1h ac

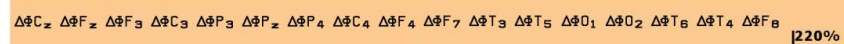

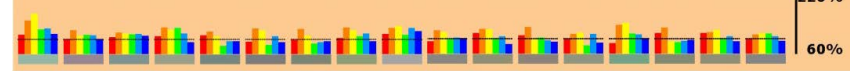

Placebo EC 2h ac

$\Delta \Phi C_{2} \Delta \Phi F_{2} \Delta \Phi F_{3} \Delta \Phi C_{3} \Delta \Phi P_{3} \Delta \Phi P_{2} \Delta \Phi P_{4} \Delta \Phi C_{4} \Delta \Phi F_{4} \Delta \Phi F_{7} \Delta \Phi T_{3} \Delta \Phi T_{5} \Delta \Phi D_{1} \Delta \Phi O_{2} \Delta \Phi T_{6} \Delta \Phi T_{4} \Delta \Phi F_{8} F_{3}{ }^{220 \%}$

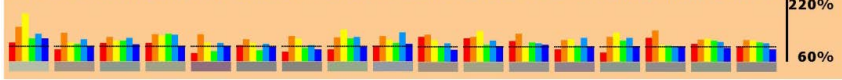

Placebo EC 3hac

$\Delta \Phi C_{2} \Delta \Phi F_{2} \Delta \Phi F_{3} \Delta \Phi C_{3} \Delta \Phi P_{3} \Delta \Phi P_{z} \Delta \Phi P_{4} \Delta \Phi C_{4} \Delta \Phi F_{4} \Delta \Phi F_{7} \Delta \Phi T_{3} \Delta \Phi T_{5} \Delta \Phi 0_{1} \Delta \Phi O_{2} \Delta \Phi T_{6} \Delta \Phi T_{4} \Delta \Phi F_{8}{ }^{220}$

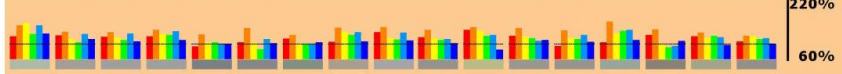

Placebo EC 4h ac

$\Delta \Phi \mathrm{C}_{\mathbf{2}} \Delta \Phi \mathrm{F}_{\mathbf{2}} \Delta \Phi \mathrm{F}_{3} \Delta \Phi \mathrm{C}_{3} \Delta \Phi \mathrm{P}_{3} \Delta \Phi \mathrm{P}_{\mathrm{z}} \Delta \Phi \mathrm{P}_{4} \Delta \Phi \mathrm{C}_{4} \Delta \Phi \mathrm{F}_{4} \Delta \Phi \mathrm{F}_{7} \Delta \Phi \mathrm{T}_{3} \Delta \Phi \mathrm{T}_{5} \Delta \Phi \mathrm{O}_{1} \Delta \Phi \mathrm{O}_{2} \Delta \Phi \mathrm{T}_{\mathrm{F}} \Delta \Phi \mathrm{T}_{4} \Delta \Phi \mathrm{F}_{\mathrm{B}}$

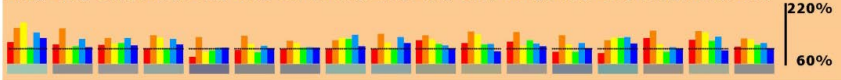

$n=23$

(a)

$80 \mathrm{mg} \mathrm{EC}$ 1h ac

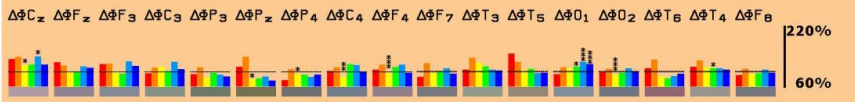

$80 \mathrm{mg} \mathrm{EC} 2 \mathrm{~h}$ ac

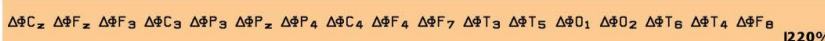

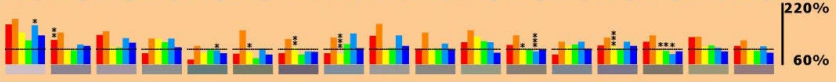

$80 \mathrm{mg}$ EC $3 \mathrm{~h}$ ac

$\Delta \Phi C_{2} \Delta \Phi F_{z} \Delta \Phi F_{3} \Delta \Phi C_{3} \Delta \Phi P_{3} \Delta \Phi P_{2} \Delta \Phi P_{4} \Delta \Phi C_{4} \Delta \Phi F_{4} \Delta \Phi F_{7} \Delta \Phi T_{3} \Delta \Phi T_{5} \Delta \Phi D_{1} \Delta \Phi 0_{2} \Delta \Phi T_{6} \Delta \Phi T_{4} \Delta \Phi F_{3}$

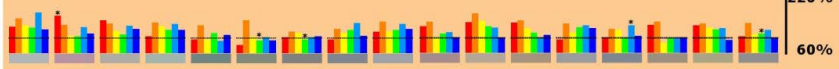

$80 \mathrm{mg} \mathrm{EC} 4 \mathrm{~h}$ ac

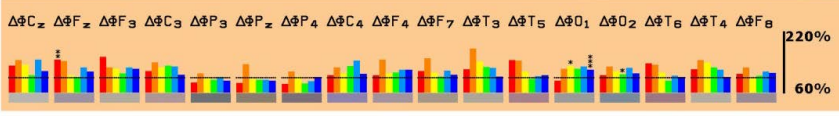

(b)

$160 \mathrm{mg}$ EC $1 \mathrm{~h}$ ac

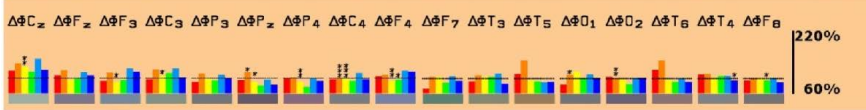

$160 \mathrm{mg}$ EC $2 \mathrm{~h}$ ac

$\Delta \Phi C_{2} \Delta \Phi F_{2} \Delta \Phi F_{3} \Delta \Phi C_{3} \Delta \Phi P_{3} \Delta \Phi P_{2} \Delta \Phi P_{4} \Delta \Phi C_{4} \Delta \Phi F_{4} \Delta \Phi F_{7} \Delta \Phi T_{3} \Delta \Phi T_{5} \Delta \Phi 0_{1} \Delta \Phi 0_{2} \Delta \Phi T_{5} \Delta \Phi T_{4} \Delta \Phi F_{3}$

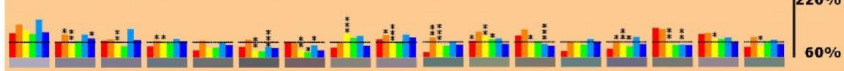

$160 \mathrm{mg}$ EC $3 \mathrm{~h}$ ac

$\left.\Delta \Phi C_{2} \Delta \Phi F_{2} \Delta \Phi F_{3} \Delta \Phi C_{3} \Delta \Phi P_{3} \Delta \Phi P_{2} \Delta \Phi P_{4} \Delta \Phi C_{4} \Delta \Phi F_{4} \Delta \Phi F_{7} \Delta \Phi T_{3} \Delta \Phi T_{5} \Delta \Phi 0_{1} \Delta \Phi 0_{2} \Delta \Phi T_{6} \Delta \Phi T_{4} \Delta \Phi F_{B}\right|^{220 \%}$

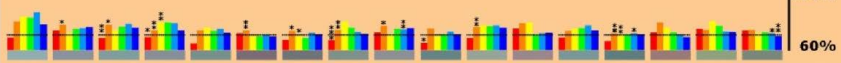
$160 \mathrm{mg}$ EC $4 \mathrm{~h}$ ac

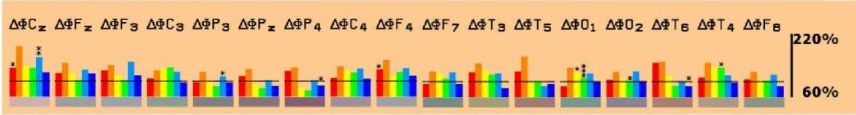

(c)

Figure 2. Percent changes in spectral power compared to baseline after single-dose (acute) administration of placebo (a), Silexan ${ }^{\circledR} 80 \mathrm{mg}$ (b) and Silexan ${ }^{\circledR} 160 \mathrm{mg}$ (c) in condition "eyes closed”. Colour coding: red—delta, orange-theta, yellowalpha1, green-alpha2, light blue-beta1, dark blue-beta2. Comparisons to placebo: ${ }^{*} \mathrm{p}<0.10 ;{ }^{* *} \mathrm{p}<0.05 ;{ }^{* * *} \mathrm{p}<0.01$. 
Table 2. Baseline spectral power $\left(\mu \mathrm{V}^{2}\right)$ for physical electrode locations for placebo (PL), Silexan ${ }^{\circledR} 80 \mathrm{mg}(80 \mathrm{mg})$ and Silexan ${ }^{\circledR} 160 \mathrm{mg}$ (160 mg) in condition “eyes closed” (M: median values across all locations).

\begin{tabular}{|c|c|c|c|c|c|c|c|c|c|c|c|c|c|c|c|c|c|c|c|}
\hline \multirow{3}{*}{ Electrode } & \multirow{3}{*}{$\mathbf{n}$} & \multirow{3}{*}{ Pl } & \multicolumn{2}{|c|}{ Delta } & \multicolumn{3}{|c|}{ Theta } & \multicolumn{3}{|c|}{ Alpha1 } & \multicolumn{3}{|c|}{ Alpha2 } & \multicolumn{3}{|c|}{ Beta1 } & \multicolumn{3}{|c|}{ Beta2 } \\
\hline & & & 80 & 160 & \multirow{2}{*}{ Pl } & 80 & 160 & \multirow{2}{*}{ Pl } & 80 & 160 & \multirow{2}{*}{ Pl } & \multirow{2}{*}{$\begin{array}{c}80 \\
\mathrm{mg}\end{array}$} & \multirow{2}{*}{$\begin{array}{c}160 \\
\mathrm{mg}\end{array}$} & \multirow{2}{*}{ Pl } & \multirow{2}{*}{$\begin{array}{c}80 \\
\mathbf{m g}\end{array}$} & \multirow{2}{*}{$\begin{array}{c}160 \\
\mathrm{mg}\end{array}$} & \multirow{2}{*}{ Pl } & \multirow{2}{*}{$\begin{array}{c}80 \\
\mathrm{mg}\end{array}$} & \multirow{2}{*}{$\begin{array}{r}160 \\
\mathrm{mg}\end{array}$} \\
\hline & & & mg & mg & & mg & mg & & mg & mg & & & & & & & & & \\
\hline $\mathrm{Cz}$ & 23 & 2.83 & 2.49 & 2.99 & 0.7 & 0.73 & 0.79 & 1 & 1.78 & 1.32 & 0.99 & 1.19 & 0.9 & 0.82 & 0.6 & 0.69 & 1.07 & 1.04 & 0.95 \\
\hline $\mathbf{F z}$ & 23 & 2.91 & 2.71 & 2.51 & 0.85 & 0.73 & 0.87 & 1.33 & 1.59 & 1.63 & 1.02 & 0.84 & 0.97 & 0.67 & 0.48 & 0.58 & 0.72 & 0.59 & 0.72 \\
\hline F3 & 23 & 2.87 & 2.22 & 2.96 & 0.68 & 0.65 & 0.81 & 1.09 & 1.48 & 1.67 & 0.97 & 0.87 & 0.83 & 0.73 & 0.55 & 0.74 & 0.99 & 0.74 & 0.93 \\
\hline C3 & 23 & 1.56 & 1.98 & 1.57 & 0.43 & 0.41 & 0.46 & 0.72 & 0.96 & 0.98 & 1.17 & 0.7 & 0.88 & 1.21 & 0.69 & 0.81 & 0.99 & 0.82 & 1.02 \\
\hline P3 & 23 & 2.22 & 2.32 & 2.19 & 0.5 & 0.55 & 0.44 & 1.44 & 2.36 & 1.41 & 1.85 & 1.34 & 1.24 & 0.93 & 0.82 & 0.75 & 0.59 & 0.56 & 0.6 \\
\hline $\mathbf{P z}$ & 23 & 3.03 & 3.42 & 2.77 & 0.82 & 0.73 & 0.57 & 2.53 & 2.64 & 1.95 & 2.99 & 3.95 & 2.79 & 0.81 & 1.01 & 0.97 & 0.55 & 0.78 & 0.63 \\
\hline P4 & 23 & 2.22 & 2.94 & 1.82 & 0.51 & 0.61 & 0.44 & 2.43 & 2.03 & 1.69 & 1.84 & 1.81 & 1.72 & 1.03 & 0.81 & 0.84 & 0.74 & 0.57 & 0.69 \\
\hline C4 & 23 & 1.86 & 2.16 & 2.18 & 0.48 & 0.57 & 0.53 & 1.1 & 1.55 & 0.9 & 1.23 & 0.93 & 1.14 & 1.27 & 0.89 & 1.11 & 1.35 & 1.31 & 1.34 \\
\hline F4 & 23 & 2.43 & 3.2 & 2.48 & 0.65 & 0.77 & 0.71 & 1.17 & 1.58 & 1.65 & 0.98 & 0.94 & 1.01 & 0.73 & 0.62 & 0.64 & 1 & 0.79 & 0.85 \\
\hline F7 & 23 & 8.07 & 7.72 & 10.11 & 1.27 & 1.37 & 1.51 & 2.8 & 3.18 & 3.47 & 2.3 & 1.63 & 2.52 & 1.3 & 1.17 & 0.47 & 1.7 & 1.48 & 1.72 \\
\hline T3 & 23 & 3.76 & 4.68 & 4.47 & 0.99 & 0.85 & 0.86 & 2.46 & 2.25 & 2.28 & 1.52 & 1.59 & 1.52 & 1.3 & 1.27 & 1.35 & 1.42 & 1.29 & 1.68 \\
\hline T5 & 23 & 4.29 & 4.39 & 3.88 & 1.27 & 1.17 & 1.29 & 6.58 & 5.79 & 6.79 & 2.76 & 2.81 & 3.11 & 2.03 & 1.94 & 2.08 & 1.26 & 1.38 & 1.17 \\
\hline O1 & 23 & 3.86 & 3.8 & 3.41 & 0.81 & 0.79 & 0.7 & 1.27 & 1.61 & 1.46 & 1.99 & 1.39 & 1.39 & 1.39 & 0.81 & 0.98 & 1.22 & 1.12 & 1.25 \\
\hline $\mathrm{O} 2$ & 23 & 3.26 & 3.96 & 3.47 & 0.85 & 0.9 & 0.93 & 1.61 & 1.54 & 1.38 & 1.87 & 2.01 & 2.03 & 1.31 & 1.29 & 1.18 & 1.39 & 1.42 & 1.46 \\
\hline T6 & 23 & 3.57 & 5.48 & 3.11 & 1.64 & 1.27 & 1.09 & 9.16 & 8.3 & 8.47 & 3.08 & 2.87 & 3.21 & 1.95 & 1.6 & 2.12 & 1.21 & 1.23 & 1.3 \\
\hline T4 & 23 & 3.89 & 3.46 & 3.89 & 1.04 & 0.92 & 0.95 & 3.02 & 2.39 & 2.38 & 1.8 & 1.89 & 1.71 & 1.6 & 1.29 & 1.46 & 1.48 & 1.28 & 1.47 \\
\hline F8 & 23 & 8.39 & 7.96 & 7.89 & 1.61 & 1.52 & 1.55 & 2.17 & 2.58 & 4.72 & 2.23 & 2 & 2.23 & 1.68 & 1.47 & 1.62 & 1.93 & 1.79 & 1.95 \\
\hline Median & 23 & 3.03 & 3.42 & 2.99 & 0.82 & 0.77 & 0.81 & 1.61 & 2.03 & 1.67 & 1.84 & 1.59 & 1.52 & 1.27 & 0.89 & 0.97 & 1.21 & 1.12 & 1.17 \\
\hline
\end{tabular}

period (Figure 2(a)) are interpreted to reflect a circadian rhythm as well as random variation. Compared to placebo single dose administration of Silexan $80 \mathrm{mg}$ (Figure 2(b)) was associated with increased power in the beta range (notably in the central and occipital regions) and an attenuation in the alpha1 range. Increases of delta and theta power were observed in the frontal and temporal regions. The pattern of differences to placebo in the Silexan $160 \mathrm{mg}$ (Figure 2(c)) was similar to that under Silexan $80 \mathrm{mg}$ although the differences to placebo were generally more pronounced after administration of the higher dose. For both Silexan doses statistically meaningful differences to placebo $(\mathrm{p}<0.1-\mathrm{p}<0.001$ ) were observed already at $1 \mathrm{~h}$ after dosing and persisted until the end of the EEG recordings at $4 \mathrm{~h}$.

As an example Figure 3 shows the colour vision brain maps obtained through electrode interpolation and colour coding and mixing of spectral power for the "eyes closed" condition at $2 \mathrm{~h}$ after single dose administration. Note, that the blue to violet shadings (observed mainly after administration of Silexan) indicate a dominance of waves in the beta range whereas the green and yellowish shadings (that were more common during the placebo period) reflect a larger proportion of alpha power. The pattern of differences between Silexan and placebo in the "eyes open" condition after single dose administration of the investigational treatments was comparable to that in the "eyes closed" condition although their magnitude was somewhat less pronounced (data not shown).

EEG assessments for repetitive (chronic) dosing were performed on the last day of each treatment period. Figure 4 shows the percent differences in spectral power between the post-dose assessments and the pre-dose baseline for the "eyes open" condition. Compared to placebo (Figure 4(a)) treatment with Silexan $80 \mathrm{mg} /$ day was associated with an increase in alpha1 power in the temporal lobe and with an increase of beta power in the frontal lobe (Figure 4(b)) that were observed during all post-baseline recordings. For Silexan $160 \mathrm{mg} /$ day 


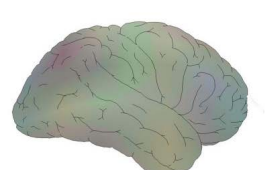

Placebo EC 2h ac

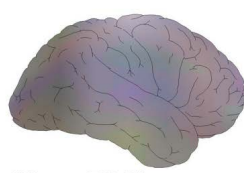

$80 \mathrm{mg}$ EC $2 \mathrm{~h}$ aC

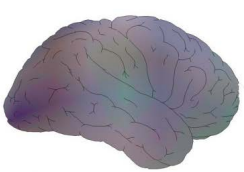

$160 \mathrm{mg}$ EC $2 \mathrm{~h}$ ac
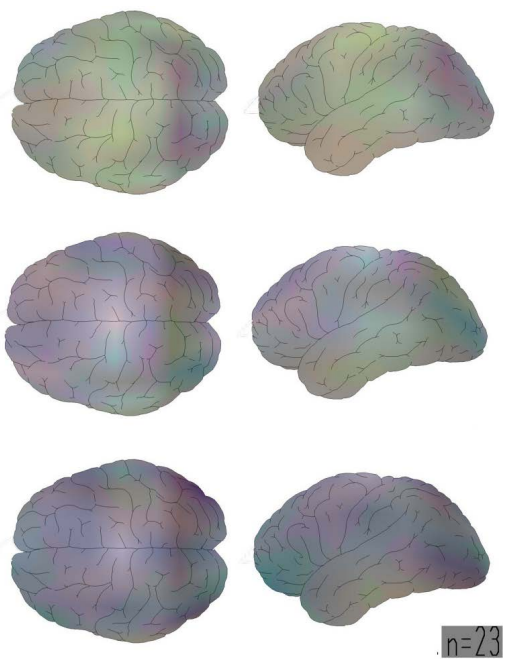

Figure 3. Spectral frequency changes $2 \mathrm{~h}$ after single dose (acute) administration of placebo (PL), Silexan ${ }^{\circledR} 80 \mathrm{mg}(80 \mathrm{mg})$ and Silexan ${ }^{\circledR} 160 \mathrm{mg}(160 \mathrm{mg})$ in condition "eyes closed" (delta through beta2 from red to blue).

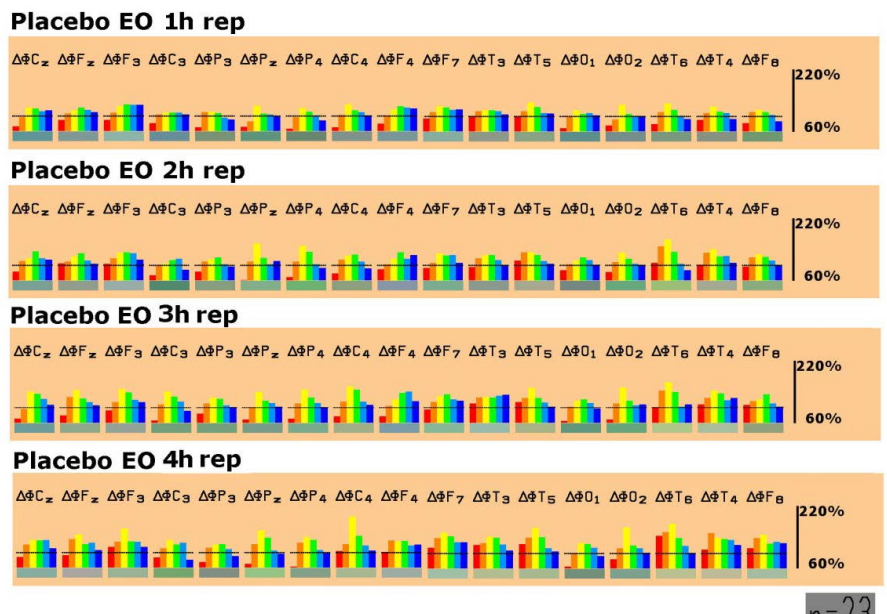

(a)

$80 \mathrm{mg}$ EO $1 \mathrm{~h}$ rep

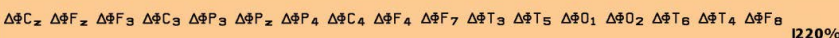

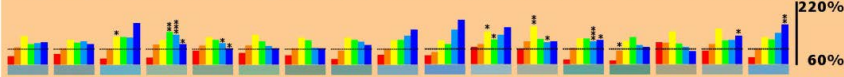

$80 \mathrm{mg}$ EO $2 \mathrm{~h}$ rep

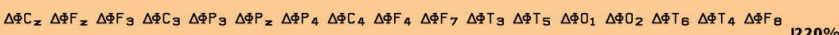

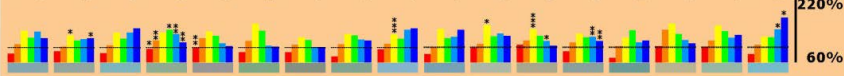

$80 \mathrm{mg}$ EO 3h rep

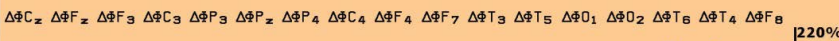

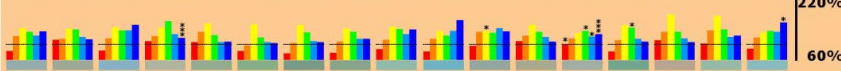
$80 \mathrm{mg} \mathrm{EO}$ 4h rep

$\Delta \Phi C_{2} \Delta \Phi F_{2} \Delta \Phi F_{3} \Delta \Phi C_{3} \Delta \Phi P_{3} \Delta \Phi P_{2} \Delta \Phi P_{4} \Delta \Phi C_{4} \Delta \Phi F_{4} \Delta \Phi F_{7} \Delta \Phi T_{3} \Delta \Phi T_{5} \Delta \Phi 0_{1} \Delta \Phi D_{2} \Delta \Phi T_{6} \Delta \Phi T_{4} \Delta \Phi F_{8}$

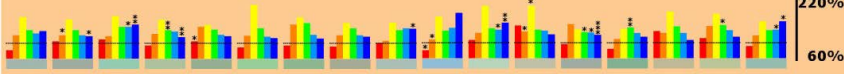




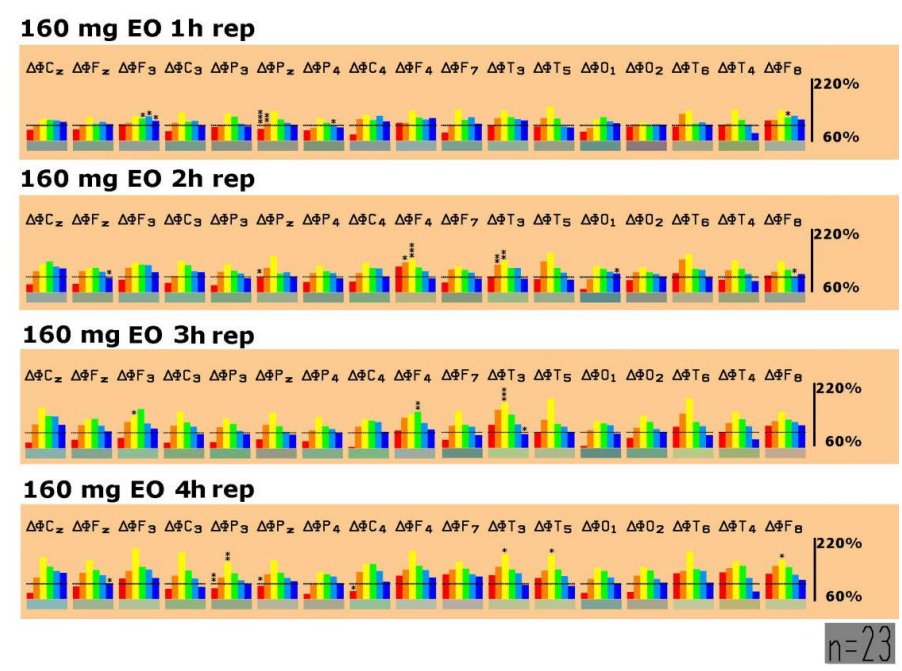

(c)

Figure 4. Percent changes in spectral power compared to baseline after repetitive-dose (chronic) administration of placebo (a), Silexan ${ }^{\circledR} 80 \mathrm{mg} /$ day (b) and Silexan ${ }^{\circledR} 160 \mathrm{mg} /$ day (c) in condition "eyes open". Colour coding: red-delta, orange-theta, yellow-alpha1, green-alpha2, light blue_-beta1, dark blue-beta2. Comparisons to placebo: ${ }^{*} \mathrm{p}<0.10 ;{ }^{* *} \mathrm{p}<0.05 ;{ }^{* * *} \mathrm{p}<0.01$.

increases of spectral power over the placebo period were observed mainly in the alpha1 frequency band (frontal, temporal, and parietal regions) as well as in the lower frequency ranges in the temporal and parietal regions (Figure 4(c)). In recording condition "eyes closed” the differences between Silexan and placebo showed a similar pattern but were less pronounced (data not shown).

Figure 5 and Figure 6 present the time courses of relative spectral power change from baseline in the frontotemporal region for recording condition "eyes open” after single and repetitive dosing of placebo in comparison to Silexan $80 \mathrm{mg}$ and $160 \mathrm{mg}$, respectively (for better legibility the area between the 2 placebo curves for single and repetitive dosing is shaded in grey). Compared to placebo a descriptively significant increase of alpha1 power which persisted throughout the 4-hour recording period was observed after repetitive dosing of Silexan ${ }^{\circledR}$ $160 \mathrm{mg}$. The results for Silexan ${ }^{\circledR} 80 \mathrm{mg}$ confirm an elevation of alpha1 power although the increase over placebo was less pronounced with the lower dose of the herbal drug.

During cognitive performance testing only minor and unsystematic differences in relative spectral frequency power change from baseline were observed between both dosages of Silexan and placebo.

\subsection{Cognitive Performance}

Across the test administrations at pre-dose as well as at 1, 2, 3, and $4 \mathrm{~h}$ post dose moderate improvements in d2 and KLT test performance were observed during all treatment periods after single and repetitive dose administration of the study drugs (including placebo). These changes can most probably be interpreted as a training effect. In the memory test the treatment condition mean values before and at the different time points after dosing showed some minor variation without exhibiting a clear trend. For all 3 cognitive tests only minor differences were observed between both dosages of Silexan and placebo.

\subsection{Safety/Tolerability}

During and within 2 days after the end of the treatment periods 4 adverse events (AEs) were observed in $4 / 23$ subjects (17.4\%) exposed to Silexan $160 \mathrm{mg} /$ day, 13 events were reported by 9/24 subjects (37.5\%) during or after the Silexan $80 \mathrm{mg}$ /day period, and 4 events occurred in 4/23 subjects $(17.4 \%)$ during or after placebo administration. Eleven out of a total of 16 AEs observed under Silexan $80 \mathrm{mg} /$ day or $160 \mathrm{mg} /$ day were gastrointestinal disorders, the most frequent of which was eructation (8 events), whereas no gastrointestinal events were observed in the placebo period. Other events observed in more than one patient within one treatment period were fatigue and increased blood triglycerides both of which occurred in two patients during placebo administration. No serious events were observed. 

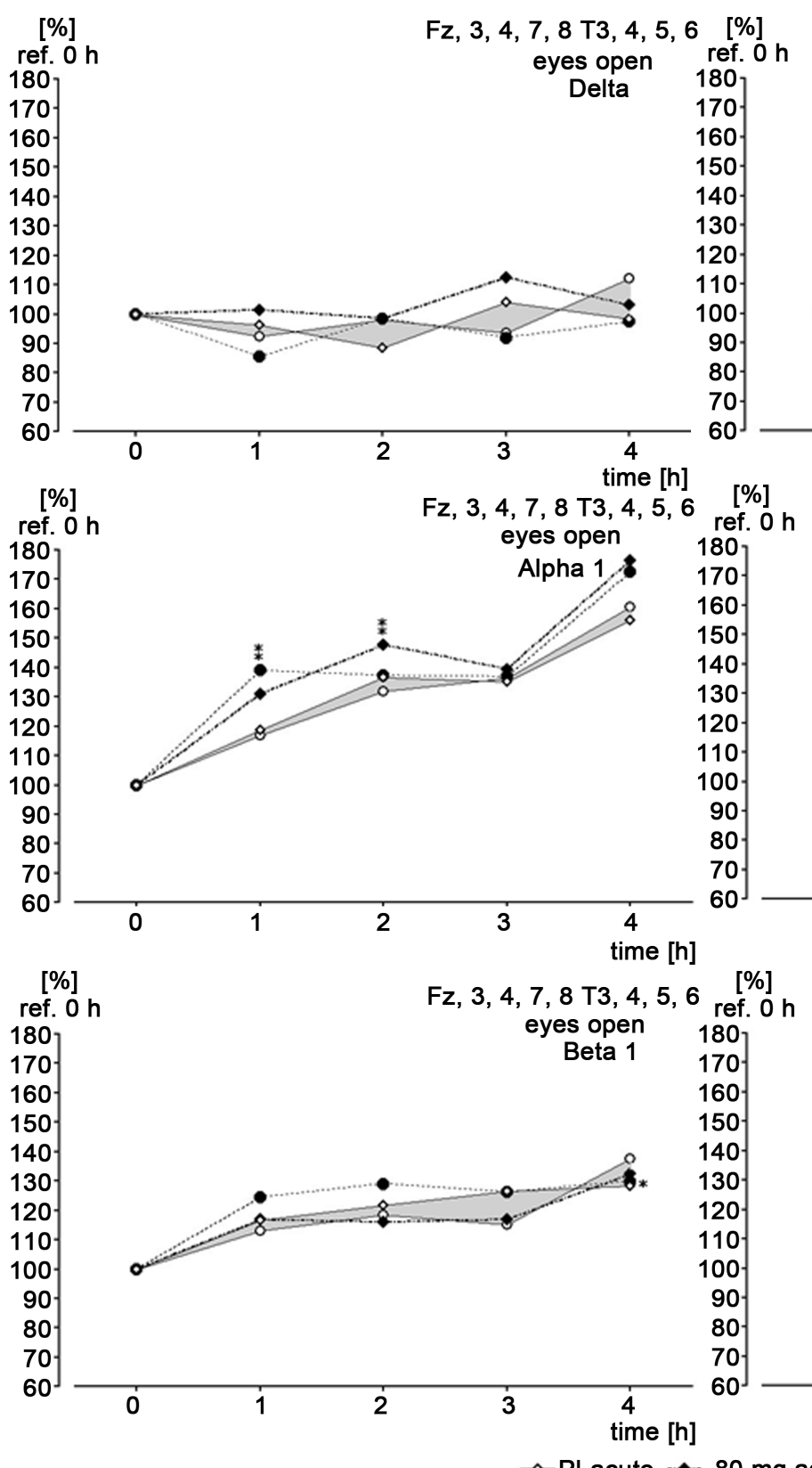

[\%]
ref. $0 \mathrm{~h}$

180
170

160.

150.

140 .

130 .

120.

110 .

100

90

80.
70.

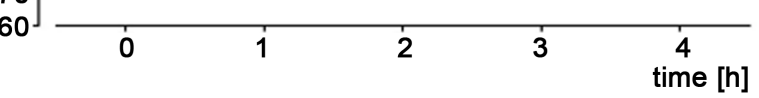

[\%]

ref. $0 \mathrm{~h}$

Fz, 3, 4, 7, 8 T3, 4, 5, 6 eyes open

Beta 2

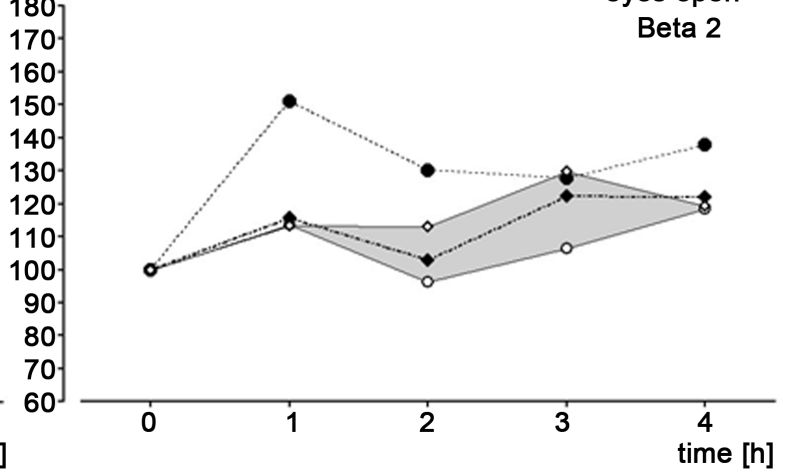

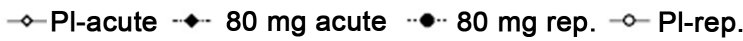

Figure 5. Time course of percent changes in spectral power in the fronto-temporal region compared to baseline after single and repetitive-dose administration of placebo (Pl) and Silexan ${ }^{\circledR} 80 \mathrm{mg} /$ day (80 mg) in condition "eyes open”. Comparisons to placebo: ${ }^{*} \mathrm{p}<0.10 ;{ }^{* *} \mathrm{p}<0.05$.

\section{Discussion}

The study indicates that daily doses of 80 and 160 mg Silexan have an objectively verifiable effect in the human brain. The most prominent functional change in the power spectrum associated with the intake of Silexan was an increase of power in the alpha1 range during repetitive administration that persisted until the end of the qEEG recordings at $4 \mathrm{~h}$ after dosing. Increased alpha activity of the brain has been associated with a state of relaxed wakefulness (e. g., [19]). In psychotherapy alpha biofeedback has been used successfully in the treatment of anxiety disorders by increasing alpha spectral power [20] [21]. These observations are consistent with the demonstrated clinical efficacy of Silexan as an anxiolytic drug [13] [14] [16] [22]. 


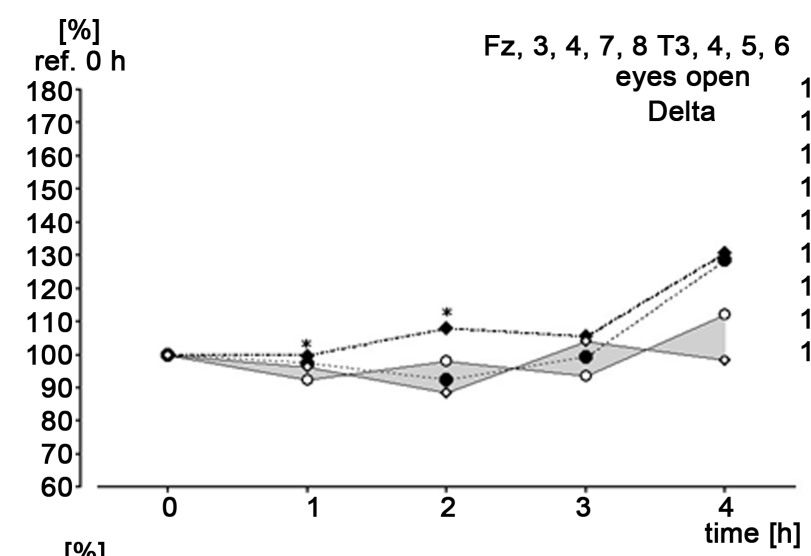

[\%]

ref. $\mathrm{h}$

170
160
150
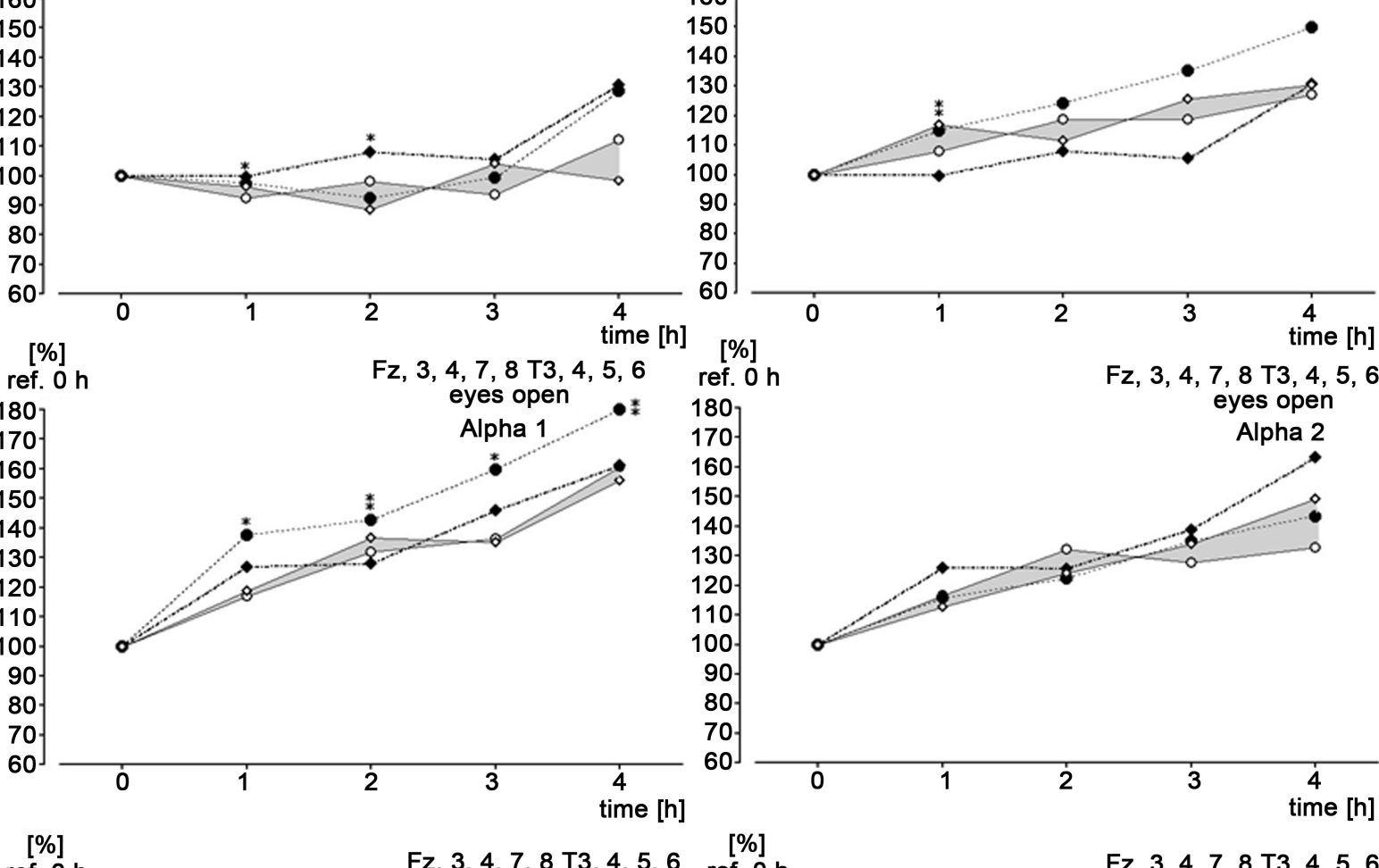

ref. $0 \mathrm{~h}$

180
170.

170.

150.

140 -

130.

120.

110 .

100.

90.

80.

70.

60

[\%]

ref. O h

${ }^{180}$ ]

170
160

150

140
130

130

110

100
90

90
80
70

60

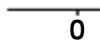

0

[\%]

ref. $0 \mathrm{~h}$

180 ]

170

160.

150.

140 .

130.

120 .

110.

100

90.

80
70.

70.

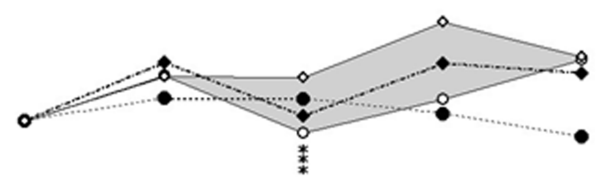

time [h]

0

2

$3 \quad \begin{gathered}4 \\ \text { time [h] }\end{gathered}$

- Pl-acute $\cdots \cdots 160 \mathrm{mg}$ acute $\cdots \bullet \cdot 160 \mathrm{mg}$ rep. $\quad$ - Pl-rep.

Figure 6. Time course of percent changes in spectral power in the fronto-temporal region compared to baseline after single and repetitive-dose administration of placebo (Pl) and Silexan ${ }^{\circledR} 160 \mathrm{mg} /$ day (160 mg) in condition "eyes open”. Comparisons to placebo: ${ }^{*} \mathrm{p}<0.10 ;{ }^{* *} \mathrm{p}<0.05$.

The repetitive administration of Silexan was neither associated with a decrease in absolute and relative alpha power, nor with an attenuation of over-all power, both of which are typically observed following the application of drugs that have a sedative effect, including sedative neuroleptics and benzodiazepines [23]. Whereas benzodiazepines and other sedating drugs have been found to significantly impair cognitive performance, and thus to interfere with essential activities of daily living like driving or operating machinery (e. g., [24]), therapeutic doses of 80 and $160 \mathrm{mg}$ Silexan did not adversely affect the subjects' performance during 3 mental challenges assessing different aspects of cognition and memory. The data of this study therefore do not provide any evidence that Silexan may exert a sedative effect.

Silexan was well tolerated by the healthy volunteers participating in this trial. No dose dependent increase of 
adverse reactions was observed, and the incidence of AEs during the $160 \mathrm{mg} /$ day period, corresponding to twice the recommended dose according to the marketing authorisation of the drug, was almost entirely on one level with that observed during exposure to placebo. Mild to moderate gastro-intestinal complaints, notably eructation, which constituted the majority of adverse events reported during the administration of Silexan in this trial, may be expected according to the safety profile of the drug and thus do not indicate any previously unknown risks of the herbal essential oil.

\section{Conclusion}

This study provides evidence that ingredients of the herbal anxiolytic drug Silexan penetrate the blood-brain barrier and induce functional changes in the CNS. The types of changes observed in the qEEG are consistent with the anxiolytic clinical effects of the drug. No sedative effects were observed. Silexan was well tolerated during repetitive administration of doses up to twice the recommended marketed dose.

\section{Acknowledgements}

We appreciate the performance of Mrs. Petra Werling with respect to EEG recordings and we thank Mrs. Leonie Schombert for documentation of the results. Mrs. Ingrid Keplinger-Dimpfel is thanked for taking care of the logistics of the study and quality control.

We thank Andreas Völp who provided medical writing services.

\section{References}

[1] Shukla, S.D., Bhatnagar, M. and Khurana, S. (2012) Critical Evaluation of Ayurvedic Plants for Stimulating Intrinsic Antioxidant Response. Frontiers in Neuroscience, 6, 112. http://dx.doi.org/10.3389/fnins.2012.00112

[2] Bhattaram, V.A., Graefe, U., Kohlert, C., Veit, M. and Derendorf, H. (2002) Pharmacokinetics and Bioavailability of Herbal Medicinal Products. Phytomedicine, 9, 1-33. http://dx.doi.org/10.1078/1433-187X-00210

[3] Jobert, M., Wilson, F.J., Ruigt, G.S., Brunovsky, M., Prichep, L.S., Drinkenburg, W.H. and Committee, I.P.-E.G. (2012) Guidelines for the Recording and Evaluation of Pharmaco-EEG Data in Man: The International Pharmaco-EEG Society (IPEG). Neuropsychobiology, 66, 201-220. http://dx.doi.org/10.1159/000343478

[4] Saletu, B., Grünberger, J. and Linzmayer, L. (1983) Quantitative Pharmaco-EEG and Performance after Administration of Brotizolam to Healthy Volunteers. British Journal of Clinical Pharmacology, 16, 333S-345S. http://dx.doi.org/10.1111/j.1365-2125.1983.tb02308.x

[5] Fink, M. and Shapiro, D.M. (1969) EEG Patterns as an Index of Clinical Activity of Psychoactive Drugs. Electroencephalography and Clinical Neurophysiology, 27, 710. http://dx.doi.org/10.1016/0013-4694(69)91372-8

[6] Itil, T.M., Ulett, G.A. and Fukuda, T. (1971) Quantitative Pharmaco-Electroencephalography in Early Evaluation of Psychotropic Drugs. Folia Psychiatrica et Neurologica Japonica, 25, 195-202.

[7] Dimpfel, W., Hofmann, H.C., Prohaska, A., Schober, F. and Schellenberg, R. (1996) Source Density Analysis of Functional Topographical EEG: Monitoring of Cognitive Drug Action. European Journal of Medical Research, 1, $283-290$.

[8] Schober, F., Schellenberg, R. and Dimpfel, W. (1995) Reflection of Mental Exercise in the Dynamic Quantitative Topographical EEG. Neuropsychobiology, 31, 98-112. http://dx.doi.org/10.1159/000119179

[9] Dimpfel, W. (2003) Preclinical Data Base of Pharmaco-Specific Rat EEG Fingerprints (Tele-Stereo-EEG). European Journal of Medical Research, 8, 199-207.

[10] Dimpfel, W. (2013) Pharmacological Classification of Herbal Extracts by Means of Comparison to Spectral EEG Signatures Induced by Synthetic Drugs in the Freely Moving Rat. Journal of Ethnopharmacology, 149, 583-589. http://dx.doi.org/10.1016/j.jep.2013.07.029

[11] Dimpfel, W., Koch, K. and Weiss, G. (2011) Early Effect of NEURAPAS ${ }^{\circledR}$ Balance on Current Source Density (CSD) of Human EEG. BMC Psychiatry, 11, 123. http://dx.doi.org/10.1186/1471-244X-11-123

[12] Hamilton, M. (1976) Hamilton Anxiety Scale (HAMA). In: Guy, W., Ed., ECDEU Assessment Manual for Psychopharmacology, US National Institute of Health, Psychopharmacology Research Branch, Rockville, 193-197.

[13] Kasper, S., Gastpar, M., Müller, W.E., Volz, H.P., Möller, H.J., Dienel, A. and Schläfke, S. (2010) Silexan, an Orally Administered Lavandula Oil Preparation, Is Effective in the Treatment of "Subsyndromal” Anxiety Disorder: A Randomized, Double-Blind, Placebo Controlled Trial. International Clinical Psychopharmacology, 25, 277-287. http://dx.doi.org/10.1097/yic.0b013e32833b3242

[14] Kasper, S., Anghelescu, I. and Dienel, A. (2010) Efficacy of Silexan (WS ${ }^{\circledR} 1265$ ) in Patients with Restlessness and 
Sleep Disturbance. Annual Congress of the German Society for Psychiatry and Psychotherapy (DGPPN), Berlin.

[15] Kasper, S., Gastpar, M., Müller, W.E., Volz, H.-P., Möller, H.-J., Schläfke, S. and Dienel, A. (2014) Lavender Oil Preparation Silexan Is Effective in Generalized Anxiety Disorder-A Randomized, Double-Blind Comparison to Placebo and Paroxetine. The International Journal of Neuropsychopharmacology, 17, 859-869.

http://dx.doi.org/10.1017/S1461145714000017

[16] Woelk, H. and Schläfke, S. (2010) A Multi-Center, Double-Blind, Randomised Study of the Lavender Oil Preparation Silexan in Comparison to Lorazepam for Generalized Anxiety Disorder. Phytomedicine, 17, 94-99. http://dx.doi.org/10.1016/j.phymed.2009.10.006

[17] Brickenkamp, R. (1994) d2-Test. Hogrefe, Göttingen.

[18] Düker, H. and Lienert, G.A. (1965) Der Konzentrations-Leistungstest (KLT). Hogrefe, Göttingen.

[19] Cantero, J.L., Atienza, M., Salas, R.M. and Gomez, C.M. (1999) Brain Spatial Microstates of Human Spontaneous Alpha Activity in Relaxed Wakefulness, Drowsiness Period, and REM Sleep. Brain Topography, 11, 257-263. http://dx.doi.org/10.1023/A:1022213302688

[20] Hardt, J.V. and Kamiya, J. (1978) Anxiety Change through Electroencephalographic Alpha Feedback Seen Only in High Anxiety Subjects. Science, 201, 79-81. http://dx.doi.org/10.1126/science.663641

[21] Rice, K.M., Blanchard, E.B. and Purcell, M. (1993) Biofeedback Treatments of Generalized Anxiety Disorder: Preliminary Results. Biofeedback and Self-Regulation, 18, 93-105. http://dx.doi.org/10.1007/BF01848110

[22] Kasper, S., Dienel, A. and Kieser, M. (2004) Continuation and Long-Term Maintenance Treatment with Hypericum Extract WS ${ }^{\circledR} 5570$ after Successful Acute Treatment of Mild to Moderate Depression—Rationale and Study Design. International Journal of Methods in Psychiatric Research, 13, 176-183. http://dx.doi.org/10.1002/mpr.173

[23] Saletu, B., Anderer, P. and Saletu-Zyhlarz, G.M. (2006) EEG Topography and Tomography (LORETA) in the Classification and Evaluation of the Pharmacodynamics of Psychotropic Drugs. Clinical EEG and Neuroscience, 37, 66-80. http://dx.doi.org/10.1177/155005940603700205

[24] Takahashi, M., Iwamoto, K., Kawamura, Y., Nakamura, Y., Ishihara, R., Uchiyama, Y., Ebe, K., Noda, A., Noda, Y., Yoshida, K., Iidaka, T. and Ozaki, N. (2010) The Effects of Acute Treatment with Tandospirone, Diazepam, and Placebo on Driving Performance and Cognitive Function in Healthy Volunteers. Human Psychopharmacology, 25, 260267. http://dx.doi.org/10.1002/hup.1105 